\title{
Analgesic Requirements in Super Morbid and Morbid Obese Bariatric Patients Undergoing Laparoscopic Sleeve Gastrectomy: A Prospective Observational Study
}

\author{
Hamed ELGENDY, MD,PhD 1.2.3; Soha ELMORSY, MD, PhD 2,5; Talha YOUSSEF , MBBS 6 ; \\ Ahmad BANJAR, MBBS 7,8 \\ 1 Department of Anesthesia, Assiut University Hospitals, Egypt \& 2 Anesthesia Dept., HAMAD Medical Corporation, Doha, Qatar \& 3 Clinical Ass. Prof. Weill Cornell \\ Medicine Qatar \\ 2 Department of Medical Pharmacology Faculty of Medicine, Cairo University; 5 Research Consultant, King Abdullah Medical City Research Center, Makkah, Saudi \\ Arabia; \\ 6 Internal Medicine Dept., Prince Mohammad Bin Abdul-Aziz Hospital, Ministry of National Guard, Al Madinah, Saudi Arabia \\ 7Medical Student trainee , Umm Al Qura University \& 8 King Abdullah Medical City; Saudi Arabia.
}

\begin{abstract}
Background and aims: Opioid analgesia is associated with serious adverse effects; hypoventilation, hypoxaemia and ileus. Our aim was to investigate analgesic requirements for super morbid obese, (SMO), (BMI $\geq 50 \mathrm{~kg} / \mathrm{m} 2$ ) when compared to morbid (MO), (BMl 40-49.9 kg/m2) individuals underwent sleeve gastrectomy and its impact on postoperative outcome.

Methods: We studied 297 consecutive patients (183 MO, 96 SMO) underwent bariatric surgery. Data analysis included perioperative anesthetic management.

Results: SMO patients exhibited higher asthmatics percentage $(P=0.016)$ and ASA III $(P<0.001)$. Lower serum albumin $(P=$ $0.001)$ and higher INR levels $(P=0.020)$ were observed in SMO patients (Table 1).

Regular laryngoscope was commonly used in MO group, while other devices was higher in $\mathrm{SMO},(\mathrm{P}=0.003)$. Higher propofol consumption, longer anesthesia time, increased crystalloid intake and urine output were observed in SMO group, respectively, $(P=0.001),(P=0.033),(P<0.001),(P=0.017)$ (Table 2). Total morphine equivalent consumption dosages and VAS score were comparable in both groups at admission, stay or leaving PACU. Vomiting was higher in $\mathrm{MO}$ group, $(\mathrm{P}=0.004)$. ICU admission was higher at SMO group $(P<0.001)$, however, PACU stay time was comparable, $(P=0.060)$ (Table 3 ).
\end{abstract}

\begin{tabular}{|c|c|c|c|}
\hline Characteristics & $\begin{array}{c}\begin{array}{c}\text { Morbidly obese } \\
(\mathrm{n}=183)\end{array} \\
\end{array}$ & $\begin{array}{c}\text { Super-Morbidlly obese } \\
(n=96)\end{array}$ & $P$-Value \\
\hline $\begin{array}{l}\text { Premedication: Midazolam } / \mathrm{mg} \\
\text { IV anaesthetics: Propofol / mg }\end{array}$ & $\begin{array}{l}0.3 \pm 0.9 \\
212.6 \pm 59.4\end{array}$ & $\begin{array}{c}0.2 \pm 0.6 \\
238.1 \pm 64.0\end{array}$ & $\begin{array}{l}0.508 \\
0.001\end{array}$ \\
\hline $\begin{array}{l}\text { Intra Operative analgesics Usage } \mathrm{n} \text { (.\%) } \\
\text { Pararectamel } \\
\text { Morphine }\end{array}$ & $\begin{array}{l}148 / 183(80.9) \\
146 / 183(79.8)\end{array}$ & $\begin{array}{l}75 / 96(78.1) \\
77 / 96(80.2)\end{array}$ & $\begin{array}{l}0.586 \\
0.933\end{array}$ \\
\hline 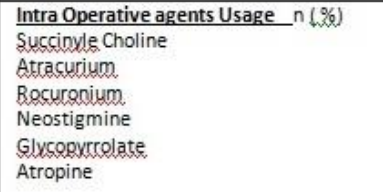 & 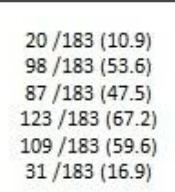 & 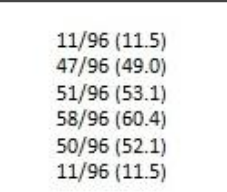 & $\begin{array}{l}0.894 \\
0.466 \\
0.375 \\
0.259 \\
0.251 \\
0.224\end{array}$ \\
\hline \begin{tabular}{|l} 
Sevoflurane \\
Destlurane
\end{tabular} & $\begin{array}{l}186 / 183(91.8) \\
15 / 183(8.3)\end{array}$ & $\begin{array}{l}89 / 96(92.7) \\
07 / 96(7.3)\end{array}$ & $\begin{array}{l}0.790 \\
0.650\end{array}$ \\
\hline $\begin{array}{l}\text { Ranitidine } \\
\text { Dexamenthasone } \\
\text { Ondansetron }\end{array}$ & $\begin{array}{l}109 / 183(59.6) \\
120 / 183(356.6) \\
144 / 183(78.7)\end{array}$ & $\begin{array}{l}49 / 96(51.0) \\
68 / 7567.08) \\
78 / 96(81.3)\end{array}$ & $\begin{array}{l}0.172 \\
0.373 \\
0.614\end{array}$ \\
\hline 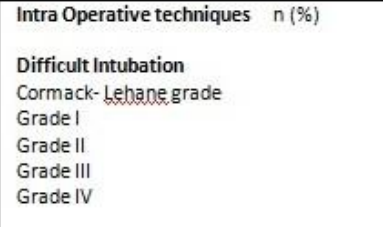 & $\begin{array}{l}08 / 183(4.4) \\
93 / 183(50.8) \\
744183(40.4) \\
14 / 1837) \\
02 / 183(1.11)\end{array}$ & $\begin{array}{l}08 / 96(8.3) \\
44 / 96(45.8) \\
46 / 96(47.9) \\
05 / 96(5.2) \\
01 / 96(1.0)\end{array}$ & $\begin{array}{l}0.176 \\
0.639\end{array}$ \\
\hline 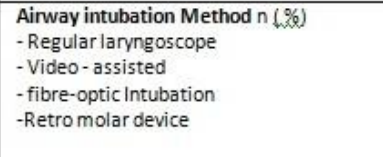 & 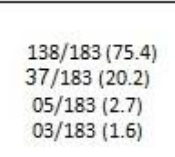 & $\begin{array}{l}57 / 96(59.4) \\
29 / 96(30.2) \\
06 / / 96(6.3) \\
04 / 96(4.2)\end{array}$ & 0.033 \\
\hline 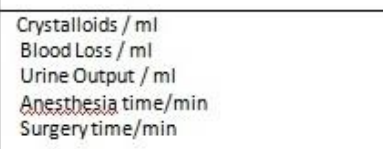 & $\begin{array}{c}2293.7 \pm 778.1 \\
19.8 \pm 7.4 \\
103.4 \pm 72.9 \\
127.7 \pm 38.1 \\
102.7 \pm 35.1\end{array}$ & $\begin{array}{l}2694.8 \pm 835.8 \\
59.0+21.2 \\
190.1 \pm 85.2 \\
1377.642 .6 \\
107.2 \pm 39.3\end{array}$ & $\begin{array}{l}<0.001 \\
0.367 \\
0.017 \\
0.033 \\
0.366\end{array}$ \\
\hline
\end{tabular}

Conclusions: We found no differences in perioperative analgesics consumption or postoperative outcome in between the studied groups except longer ICU stay, prolonged anesthesia time, increased crystalloid intake and urine output.

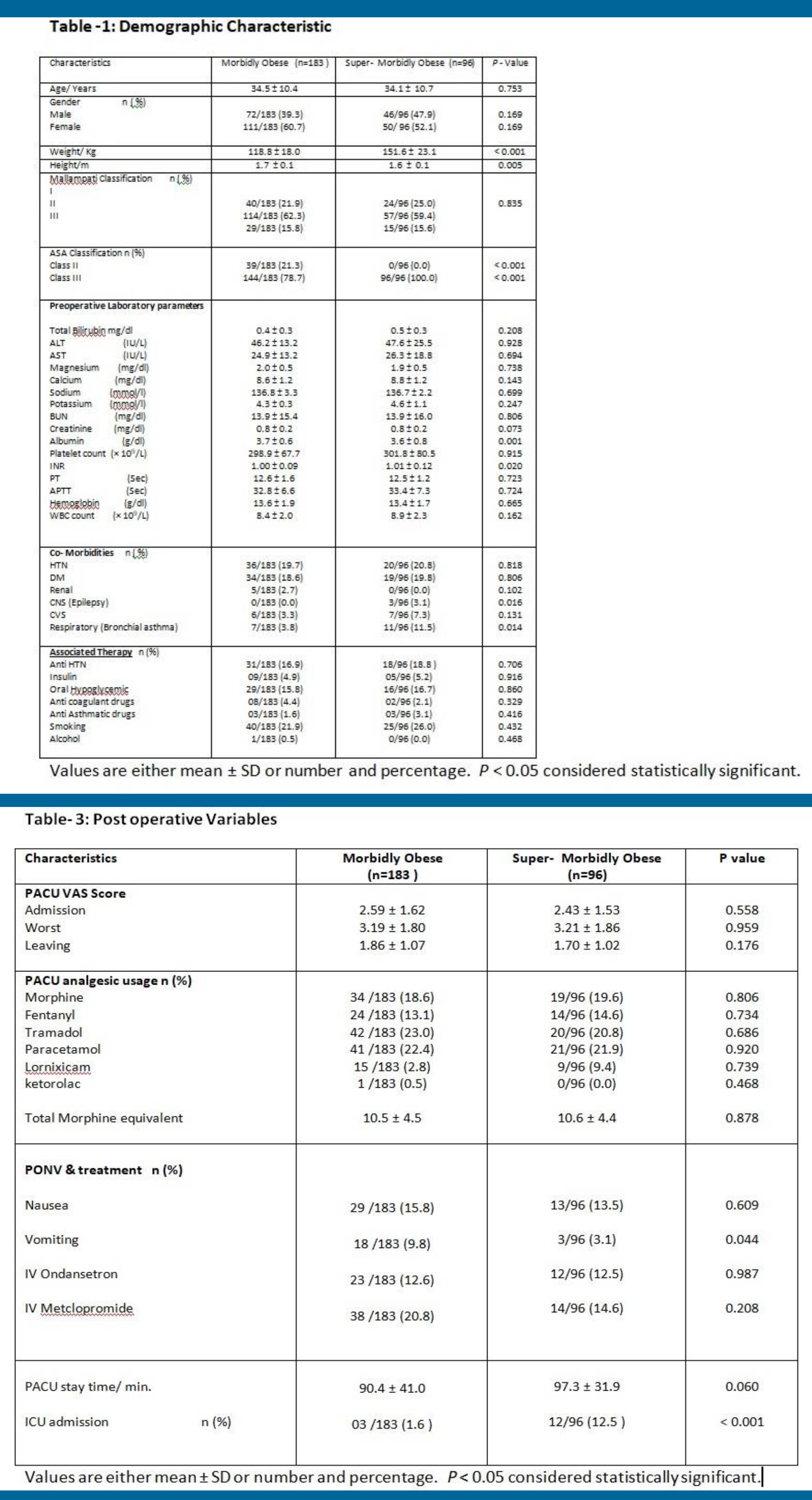

